\title{
ARTHUR RAMOS E DURVAL MARCONDES: HIGIENE MENTAL, PSICANÁLISE E MEDICINA APLICADAS À EDUCAÇÃO NACIONAL (1930-1950)
}

\author{
Ronaldo Aurélio Gimenes Garcia *
}

RESUMO: No presente artigo procuraremos analisar criticamente a proposta das clínicas de higiene mental escolar criadas nas primeiras décadas do século XX por Durval Marcondes em São Paulo e Arthur Ramos no Rio de Janeiro. O objetivo das clínicas escolares era receber as crianças tidas como incapazes de aprender. $\mathrm{O}$ estudo das respectivas propostas de intervenção na escola por meio da higiene mental e da psicanálise nos permitiu identificar o conceito de infância, família e educação. A pesquisa desenvolvida utilizou como fonte a produção intelectual dos autores a partir de obras publicadas. $\mathrm{O}$ resgate do pensamento e da prática de Marcondes e Ramos é uma forma de retomar a memória intelectual daquele período histórico, especialmente, do campo do conhecimento da história e da educaçáo.

Palavras-chave: História da educação. Arthur Ramos. Durval Marcondes. Psicanálise. Higiene mental.

\section{ARThur Ramos and DuRval Marcondes: Mental hygiene, PSYCHOANALYSIS AND MEDICINE APPLIED TO NATIONAL EDUCATION (1930-1950).}

\begin{abstract}
In the present article we aim to critically analyze the proposal of the school mental hygiene clinics created in the first decades of the 20th century by Durval Marcondes in São Paulo and Arthur Ramos in Rio De Janeiro. The objective of the school clinics was to receive the children deemed as incapable to learn. The study of the respective proposals of intervention in the school by means of mental hygiene and psychoanalysis allowed the identification of the concept of infancy, family and education. As research sources, this investigation used the published intellectual production of the authors. By retrieving the thought and practices of Marcondes and Ramos we can recover the intellectual memory of that historical period especially regarding the fields of history and education.
\end{abstract}

Keywords: History of education. Arthur Ramos. Durval Marcondes. Psychoanalysis. Mental hygiene.

\footnotetext{
* Universidade Federal da Fronteira Sul - Campus de Realeza, Realeza, Paraná, Brasil. E-mail de contato gimenesgarcia@uol.com.br.
} 


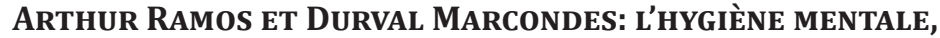 LA PSYCHANALYSE ET LA MÉDECINE APPLIQUÉES À L'ÉDUCATION NATIONALE (1930-1950).
}

\begin{abstract}
RÉSUMÉ: Dans le présent article nous chercherons à analyser critiquement la proposition des cliniques d'hygiène mentale scolaire créées dans les premières décennies du XXème siècle par Durval Marcondes à São Paulo et celles créées par Arthur Ramos à Rio de Janeiro. L'objectif des cliniques scolaires était de recevoir les enfants considerés comme incapables d'apprendre. L'étude des propositions d'intervention à l'école par l'hygiène mentale et de la psychanalyse nous a permis d'identifier le concept d'enfance, de famille et d'éducation. La recherche développée a eu comme source la production intellectuelle des auteurs à partir d'œuvres publiées. La reprise de la pensée et de la pratique de Marcondes et Ramos est une forme de reprendre la mémoire intellectuelle de cette période historique spécialement du champ de la connaissance de l'histoire et de l'éducation.
\end{abstract}

Mots-clés: Histoire de l'éducation. Arthur Ramos. Durval Marcondes. Psychanalyse. L'hygiène mentale.

\section{Introdução}

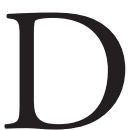

esde o ano de 2003 venho realizando alguns estudos particulares sobre a obra de Arthur Ramos. No início minha preocupação era compreender a contribuição do autor para o estudo da cultura negra no Brasil e seus desdobramentos sociais, políticos e ideológicos. Por intermédio dessas leituras preliminares pude constatar que se tratava de um pensamento singular no contexto histórico em que surgiram as primeiras obras de conteúdo antropológico no país. Na realidade estavam nascendo os pioneiros estudos de uma interpretação da realidade nacional, bem como, uma proposta de nação para o século XX.

Em janeiro de 2004 o Jornal Folha de São Paulo, em seu suplemento "Mais", trouxe um artigo sobre o livro do antropólogo norte-americano Jerry Dávila da Universidade de Duke. Com o título Diploma of whiteness: race and social policy in Brazil (1917-1945), o referido autor afirmava ter existido um projeto de eugenia no Brasil naquele período e que fora financiado pela ditadura varguista com o apoio de importantes intelectuais como Gustavo Capanema, Manoel Lourenço Filho, Arthur Ramos e outros colaboradores da Escola Nova. Ainda segundo o artigo, uma das fontes de pesquisa de Dávila foi a obra "A criança problema" de Ramos, publicada pela primeira vez em 1936 e com várias ediçóes posteriores. Nesse livro haveria uma justificativa pseudocientífica para excluir as crianças pobres e negras da escola pública. 
Fiquei muito instigado a prosseguir com meus estudos e conhecer melhor as preocupaçóes de Arthur Ramos no campo da pedagogia. Ao ler a publicação que foi fonte para a pesquisa de Jerry Dávila tive uma grande surpresa. Logo no prefácio de sua obra, Arthur Ramos faz uma severa crítica ao Governo de Getúlio Vargas e o acusa de querer instalar no país um modelo educacional de caráter autoritário e de culto à figura do governante. Além disso, Ramos demonstra uma aguda consciência em relação aos problemas sociais que atingiam diretamente as crianças pobres que frequentavam as escolas públicas do Rio de Janeiro na década de 1930.

Algum tempo depois, durante minhas pesquisas, descobri o trabalho do também médico e psiquiatra Durval Marcondes, que foi contemporâneo de Ramos e viveu em São Paulo. Como o médico alagoano, Marcondes teve um papel importante na implantação da psicanálise no Brasil e desenvolveu um projeto semelhante, em São Paulo, de assistência às crianças das escolas públicas em uma clínica criada pelo governo paulista para atendimento e orientação dos escolares considerados incapazes de aprender.

A partir dessas leituras uma série de questôes foram levantadas, demandando um trabalho investigativo que pudesse lançar luz sobre à história da educação, psicanálise e medicina nas primeiras décadas do século XX. Dávila (2006) teria feito um estudo equivocado da obra de Ramos? Haveria realmente um projeto de eugenia no Brasil da Era Vargas e que contou com a colaboração dos membros da Escola Nova? Se isso de fato ocorreu, como conciliar os ideais de uma escola pública e democrática, defendida pelos escolanovistas, com a exclusão das crianças negras e pobres? Quais eram as propostas pedagógicas de Ramos e Marcondes? Que modelo de intervençáo propunham nas escolas públicas? Que semelhanças e diferenças podem ser estabelecidas entre os projetos desenvolvidos pelos referidos médicos? A partir dessas dúvidas e de outras que foram surgindo com o levantamento bibliográfico e de fontes realizou-se uma pesquisa a partir das obras: A criança problema de Arthur Ramos e Noçóes gerais de higiene mental da criança de Durval Marcondes.

O projeto educacional de Anísio Teixeira e seus colaboradores (como era o caso de Arthur Ramos) estava claramente alicerçado nas teorias do liberalismo, da democracia, do cientificismo e do industrialismo. Não restava dúvida que visava preparar o Brasil para o século XX e, ao mesmo tempo, era uma proposta que tinha por objetivo superar os dramáticos problemas do nosso passado colonialista, escravista, rural e notoriamente desigual. Abrir as portas da escola pública para receber o maior número possível de alunos, permitir a convivência dos desiguais, inserir uma nova proposta pedagógica e romper com o modelo de escolas confessionais, privadas e excludentes eram vistos como uma ameaça para a sociedade ainda com fortes traços patrimonialistas. 
As ideias liberais dos escolanovistas, como era o caso de Anísio Teixeira e seu grupo, embora rompessem com muitas das instituiçóes que nos prendiam ao nosso passado colonialista, não contaram com o apoio de nenhum setor da população, a não ser alguns poucos intelectuais também originários da elite agrária nacional. Não havia, portanto, uma mobilização popular em prol da implantação do projeto reformista dos pioneiros. Por outro lado, era preciso também considerar que os membros do Movimento Escola Nova possuíam de fato um ideal salvacionista para o Brasil por meio da educação. Havia uma inabalável crença no poder redentor da ciência. Havia uma confiança absoluta no valor do conhecimento científico como mecanismo de superação das dificuldades nacionais.

Arthur Ramos e Durval Marcondes foram intelectuais que tiveram uma formação médica em psiquiatria e não restringiram sua atuação a esse campo específico, mas alargaram as fronteiras do conhecimento com a anexação de novas ciências como a antropologia e a psicanálise. Ambos viam na ciência uma possibilidade de intervenção social que teria a educação como meio fértil para a construção de uma nova nação democrática, moderna e desenvolvida.

\section{Arthur Ramos: vida breve e intensa produção intelectual}

Arthur Ramos de Araújo Pereira nasceu na cidade de Pilar, no Estado de Alagoas, em 07 de julho de 1903. Morreu aos 46 anos, no dia 31 de outubro de 1949, em Paris. Nessa ocasião iniciava seu trabalho junto a Unesco. Desde muito jovem Ramos teve íntimo contato com os livros, especialmente os da biblioteca que havia na casa dos pais. No ambiente familiar, além da valorização da cultura letrada, havia também muita música, especialmente valsas e cançóes populares. Além das leituras diárias Arthur Ramos também tinha o hábito de acompanhar o pai em suas visitas e consultas.

Em 1921 ingressou na Faculdade de Medicina da Bahia, uma das instituiçôes de ensino médico mais antigas do Brasil. Ali concluiu o curso em 1926. Nesse mesmo ano defendeu a tese de doutorado intitulada Primitivo e Loucura. Este trabalho lhe conferiu o título de Doutor em Ciências Médico-cirúrgicas. Em 1927 recebeu o prêmio "Alfredo Brito" em virtude do seu estudo em medicina legal, desenvolvido naquele estabelecimento de ensino.

Um conceito importante desenvolvido pelo sociólogo francês Pierre Bourdieu (1987) nos permite compreender melhor a trajetória intelectual de Arthur Ramos. Tratava-se do conceito de habitus. Referia-se a uma série de comportamentos e atitudes que o indivíduo foi adquirindo ao longo da vida e que teria influência decisiva na posiçáo que o mesmo iria ocupar no interior do campo intelectual. Assim Miceli (1987, p. XLVII) definiu habitus: 
O habitus constitui a matriz que dá conta da série de estruturações e reestruturações porque passam as diversas modalidades de experiências diacronicamente determinadas dos agentes. Assim como o habitus adquirido através da inculcação familiar é condição primordial para a estruturação das experiências escolares, o habitus transformado pela ação escolar constitui o princípio de estruturação de todas as experiências ulteriores, incluindo desde a recepção das mensagens produzidas pela indústria cultural até as experiências profissionais.

A trajetória de Ramos o credenciava para ocupar o espaço que ele desempenhou no interior do campo. Vindo de uma família tradicional do interior nordestino, proprietária e de cultura mais refinada, recebeu forte influência desse meio. O contato com bons livros, o acesso a bibliotecas, boa música, cinema e cuidadosa formação escolar em colégio confessional, levaram-no a adquirir um valioso capital cultural que, somado ao econômico, permitiu que o jovem de Pilar logo se tornasse respeitado e reconhecido por seus pares. Beneficiou-se, também, das recomendações que outros intelectuais já consagrados lhe conferiram, como ocorreu na visita de Afrânio Peixoto à Faculdade de Medicina da Bahia e dos elogios que dele recebeu pelos trabalhos ali desenvolvidos. Enquanto pensador atuante publicou artigos para jornais, editou livros, participou ativamente dos movimentos sociais e profissionais que lhe deram uma boa visibilidade no campo intelectual.

As possibilidades se ampliaram quando o médico alagoano se transferiu para o Rio de Janeiro. Chegava para constituir um grupo de pensadores que tinha uma trajetória semelhante, como Anísio Teixeira e Afrânio Peixoto. Eram nordestinos, de famílias rurais abastadas e formação educacional semelhante. Tratava-se, portanto, de um grupo em disputa com outras fraçóes de classe pela hegemonia no interior do campo. O que mudava a partir de então era a dimensão das polêmicas e a diversidade maior de grupos em conflito do que havia em Salvador. Essa aproximação entre estes intelectuais já era relativamente estimulada, uma vez que:

[...] o espaço social está construído de tal modo que os agentes que ocupam posições semelhantes ou vizinhas estão colocados em condiçóes semelhantes, e têm toda a possibilidade de possuírem disposiçóes e interesses semelhantes, logo, de produzirem práticas semelhantes. (BOURDIEU, 2004, p. 155)

No início do ano 1934 Ramos foi convidado por Anísio Teixeira, que naquele momento conduzia a educação do Rio de Janeiro, para chefiar o Serviço de Ortofrenia e Higiene Mental (SOHM) do Instituto de Pesquisas Educacionais da Secretaria da Educação. Naquele espaço abria-se a possibilidade do jovem médico pôr em prática suas hipóteses, conhecer melhor as condiçóes de vida da 
população pobre da Capital da República. O objetivo do órgão era receber as crianças tidas como agressivas, de comportamento difícil e com dificuldades de aprendizagem para um diagnóstico e possível tratamento. Logo Ramos percebeu que não se tratava de crianças "anormais", como eram logo taxadas pelas escolas, mas vítimas das adversas condições sociais do país no período entre guerras. Como resultado desse trabalho publicou: A criança problema; A familia e a escola; Educação dos pais e Saúde do espírito. Em uma carta de Anísio Teixeira, depois que esse deixou a Secretaria da Educação, endereçada ao amigo de Alagoas, ele afirmava suas expectativas quanto aos resultados promissores do serviço.

Entre tantas coisas que ensaiamos no Departamento de Educação, o seu serviço e o de Miss Williams pareceram-me sempre os mais profundos, aqueles que mudaram um pouco a própria qualidade do processo educativo. Tudo mais era acréscimo, retificação, ajuste destinado a um melhoramento de eficiência no que se vinha sempre fazendo. A seção de ortofrenia e higiene mental era uma mudança de plano. Era um ensaio de educação moral científica. Era, francamente, uma aventura para o dia d'amanhá. Em nenhum outro serviço, afirmamos, mais vigorosamente a nossa confiança na ciência. (TEIXEIRA, 1952, pp. 11-12)

Depois da demissão de Anísio Teixeira da pasta da educação do Distrito Federal, Arthur Ramos ainda permaneceu no serviço de higiene mental quando veio a instalação do Estado Novo em 1937 e a perseguição política a todos os possíveis inimigos da ordem. Em 1939 ele deixou o SOHM por não concordar com o descaso com que o Governo Federal vinha tratando o trabalho lá desenvolvido. Descontente com a ditadura, manifestou publicamente sua indignação. Na década de 1940, Arthur Ramos passava a dedicar-se intensamente à luta política contra o racismo. Atuou em vários movimentos como a Frente Negra Brasileira, a Convenção Negra Brasileira, o Instituto Internacional de Estudos Afro-Ameríndios. Em 1942, por meio da Sociedade Brasileira de Antropologia e Etnologia, lançou o Manifesto contra o racismo. Sua obra e suas lutas o levaram a realizar diversas viagens ao exterior, expondo suas ideias e compartilhando experiências de pesquisas.

Em 1949, quando Ramos foi convidado para trabalhar na Unesco, já era conhecido como autoridade intelectual no campo e referência para muitos trabalhos que vieram depois. Viu nesta oportunidade um meio de projetar-se internacionalmente e representar o Brasil em um órgão internacional. Isto se fazia por meio de uma dedicação constante à ação educativa. Esta seria a mais alta missão humana. Ramos e seu grupo de intelectuais nordestinos, especialmente, tinham um compromisso maior do que pesquisar e comunicar ideias. Mais do que isso, se viam como verdadeiros educadores capazes de transformar a realidade pelo ensino e aplicação da ciência. 


\section{Durval Marcondes: entre a psicanálise, a medicina e a educação}

Em termos gerais podemos dizer que nas primeiras décadas do século XX o Brasil, embora enfrentando diversos problemas sociais e políticos, apresentava uma refinada elite intelectual que mantinha intensos contatos com o que mais recente surgia nos países europeus e Estados Unidos. A obra de Sigmund Freud, que estava sendo editada naquele período, já era lida e discutida por diversos profissionais, especialmente os da medicina.

Em cidades como São Paulo, Rio de Janeiro e Porto Alegre simpatizantes da ciência de Freud, especialmente os profissionais da medicina, chegaram a criar associações de psicanálise (MOKREJS, 1986), onde eram debatidos os mais diversos temas da área por meio de palestras, encontros e congressos. Além disso, publicavam os estudos e promoviam cursos para formação de psicanalistas. Em muitos casos as aulas eram ministradas por professores europeus convidados.

A psicanálise foi apenas uma das ciências que se destacaram entre os pensadores brasileiros. Podemos também citar o caso da psicologia, da antropologia, da medicina legal, da psiquiatria, entre outras. Percebe-se uma confiança muito grande no poder das descobertas científicas para resolver os graves dramas da nação brasileira. O Estado, enquanto um agente de implantação e gestão das diversas políticas públicas, já era pensado, reivindicado e posto em prática ainda que de maneira experimental e com pouco tempo para mostrar seus resultados.

Durval Bellegarde Marcondes foi pioneiro, ao lado de Arthur Ramos e outros intelectuais, no estudo e na aplicação da psicanálise, principalmente na área da educação. Marcondes nasceu na cidade de São Paulo em 1899. Em 1924 formou-se em medicina pela então recém-criada Faculdade de Medicina de São Paulo. Nesse mesmo ano entrou para o serviço público estadual como médico psiquiatra da Inspetoria de Higiene Escolar e Educação Sanitária da Secretaria de Educação de São Paulo. Em parceria com o também médico Franco da Rocha fundou, em 1927, a Sociedade Brasileira de Psicanálise. Como Ramos, manteve correspondência com Sigmund Freud. Nesse período fundou também a Revista Brasileira de Psicanálise. Ainda no serviço público, criou o serviço de higiene mental escolar e instituiu uma equipe multidisciplinar de profissionais para atuar no órgão. Foi professor de psicologia social da Escola Livre de Sociologia e Política de Sáo Paulo e professor convidado de Higiene Mental da Faculdade de Higiene e Saúde Pública da Universidade de São Paulo (USP). Segundo Sagawa (2002), em 1938, por meio de decreto, foi criada a Seção de Higiene Mental Escolar. Nessa ocasião o serviço passava a contar com mais de 70 profissionais sob a coordenação de Durval Marcondes. Realizou diversas viagens ao exterior para conhecer instituiçôes de saúde mental, além de participar de reuniôes científicas. 
Participou também da criação do curso de psicologia da USP na década de 1950 e foi professor de psicologia clínica até sua aposentadoria compulsória em 1969.

Intimamente relacionada com os estudos psicanalíticos estava a chamada área da higiene mental. Era muito comum que aqueles profissionais da medicina, interessados em psicologia e psicanálise, também se dedicassem a esta nova modalidade do conhecimento científico da época. A higiene mental funcionava mais como uma forma de terapia, mas, segundo Durval Marcondes e Arthur Ramos, sua principal função seria prever futuros casos de "desajustes" e "traumas" que seriam mais difíceis de reverter em idade adulta. O próprio termo ortofrenia tinha a conotação de "corrigir" ou "consertar o que estava torto". Em última instância, a função maior do movimento higienista aplicado à saúde mental era prever e tratar dos sintomas ligados às perturbações mentais:

A moléstia mental do adulto é, o mais das vezes, o produto final de um processo de desadaptação que, sob formas diversas já se vinha manifestando desde a época infantil. A clínica em apreço vai surpreender e tratar esse processo em seu início, quando são maiores as probabilidades de sua solução. (MARCONDES, 1946, p. 44)

Tanto em Durval como em Ramos a infância era vista como um período essencial para o desenvolvimento futuro do adulto. Zelar pelo crescimento harmonioso do indivíduo era visto como essencial para se evitar o surgimento de pessoas desajustadas e despreparadas para o convívio social saudável. A criança é antes de tudo um ser que inspira cuidados de pais, professores e médicos que possuem um contato mais direto com o menor e sua família. Trata-se de um ser plenamente moldável que absorve as influências do meio social e cultural em que vive. Assim, o papel da medicina e da psicanálise era importante para orientar a educação dos pequenos, fornecendo subsídios para o trabalho pedagógico e, em certos casos, intervindo para solucionar casos em que o problema já estava posto.

Durval observou que a origem de grande parte dos problemas da infância estava relacionada à questão social ou psicológica. Eram raros os casos de crianças que possuíam dificuldades relacionadas apenas a um problema de origem "anátomo-fisiológico". Essa mesma observação Ramos já havia feito em seu trabalho no Rio de Janeiro junto ao Serviço de Ortofrenia e Higiene Mental.

Embora tivesse uma produção intelectual mais reduzida se comparada com a de Arthur Ramos e mais restrita à área medica e psicanalítica, Marcondes foi inovador em vários aspectos, a começar pela preocupação que tinha com a dimensão da psique humana. Tinha consciência de que muitas moléstias não tinham origem apenas orgânica e biológica, mas possuía toda uma rede de relaçóes que envolvia aspectos sociais, psicológicos e fisiológicos. Envolveu-se por muitos anos 
na incorporação da psicanálise como campo específico do conhecimento científico e atuou em diferentes frentes de combate, inclusive com membros de sua própria categoria profissional. A introdução da psicanálise na clínica de higiene mental escolar era um esforço no sentido de dar uma resposta à sociedade e àqueles que questionavam sua aplicabilidade.

\section{Os serviços de higiene mental escolar}

Os serviços de higiene mental são derivados das instituiçôes europeias, principalmente francesas, que remontam as experiências de Pinel e dos chamados sanatórios mentais. Na realidade eram locais de depósitos de seres humanos, todos mentalmente perturbados e, portanto, obrigados a viver separados e apartados do convívio social. A esta atmosfera de sofrimentos e torturas eram submetidos os pacientes tidos como deficientes mentais.

O primeiro serviço de higiene mental surgiu nos EUA em 1907 e de lá se espalhou para o mundo inteiro. A denominação higiene mental permaneceu até 1950, quando por indicação da Organização Mundial de Saúde (OMS) passou a adotar a terminologia saúde mental, que se mantém até hoje. O objetivo das seções de higiene mental era realizar um trabalho preventivo com as crianças. Estas eram tidas como o alvo principal dos serviços, uma vez que um trabalho desde a infância ajudava a evitar futuros problemas de neuroses e de comportamento inadequados na vida social. No Brasil, o movimento de higiene mental chegou em 1923, quando foi fundada a Liga Brasileira de Higiene Mental por Gustavo Riedel. A mencionada instituição teria uma dupla função, tanto terapêutica quanto preventiva. Sendo que para Ramos esta era a mais importante. O público alvo era formado por menores, uma vez que:

\footnotetext{
Desde cedo se verificou que estava na infância o principal campo de ação da higiene mental. Se esta visa a prevenção das doenças mentais e ao ajustamento da personalidade humana, é para a criança que deve voltar suas vistas, pois aí estão os núcleos de caráter da vida adulta. Ajustar a criança ao seu meio é o objetivo básico, o trabalho inicial, a ser continuado depois, no ajustamento do indivíduo aos seus sucessivos círculos de vida. (RAMOS, 1950, p. 20)
}

$\mathrm{O}$ atendimento em higiene mental estava estruturado no formato de uma clínica, com os seguintes profissionais: professores, assistentes sociais, professores visitadores, psicólogo, médico e psiquiatra. Vários exames e testes eram realizados, como o psicológico e pedagógico (aptidóes), o físico e aqueles para verificar todos os tipos de desajustamento emocional: 
A higiene mental infantil tem assim os aspectos largos. $\mathrm{O}$ seu campo de ação é imenso. O seu trabalho é duplo: preventivo e corretivo. Ela estuda o desenvolvimento e formação nos hábitos da primeira e segunda infância, acompanha o escolar no período da escola primária, assiste ao desabrochar da adolescência, prepara o jovem para ser a perfeita adaptação à vida adulta. (RAMOS, 1950, p. 21)

A clínica de higiene mental escolar de São Paulo contava com uma equipe constituída por diferentes profissionais, entre os quais: um médico clínico; um psicologista; visitadora, que geralmente era uma assistente social, e um médico psiquiatra. As clínicas de higiene mental possuíam, portanto, uma ampla esfera de atuação e visavam exercer um forte controle sobre o comportamento dos educandos, moldando-os de acordo com os hábitos socialmente aceitáveis. À primeira vista esta ideia podia parecer estranha, uma vez que as condiçóes sociais da maioria das crianças que frequentavam as escolas públicas da capital da República eram precárias e um trabalho de caráter preventivo como este teria muitas dificuldades para atingir seus objetivos. Nesse aspecto, Ramos apresentou uma clara consciência social do alcance do projeto que estava propondo. Na introdução de sua obra $A$ criança problema o autor mencionava a questão social no Rio de Janeiro da época como o maior obstáculo para êxito do programa de higiene mental:

As causas geradoras de problemas se ampliaram de maneira trágica, no Rio de Janeiro. Em primeiro lugar estão as condiçôes criadas pela própria guerra, o que pela segunda vez neste século, veio convulsionar o mundo e complicar o problema dos ajustamentos pacíficos entre os homens. Em seguida estão as próprias condiçốes deficitárias no Brasil, em especial no Rio de Janeiro. Crise alimentar. Crise de Habitaçôes. Índices assustadores de mortalidade e morbidade infantis. Fatores deficitários em todos os sentidos, que vieram complicar tremendamente o problema da assistência aos menores [...] Nunca a higiene mental teve que lidar com tantos primários, que converteram a capital do país num grande feudo urbano, desprotegido e entregue a sua própria sorte. Com razão se poderia achar uma atividade desnecessária ou inócua. Um serviço mental que tivesse essas causas próprias, tão grosseiras e tão deprimentes. (RAMOS, 1950, p. 8)

Podemos perceber que o médico admitia que uma sociedade em péssimas condiçóes materiais, como a brasileira neste período, a atuação de um serviço de higiene mental era muito difícil. Tentar amoldar indivíduos miseráveis em uma forma de sociedade em crise e deficitária era inviabilizar este trabalho. Ramos parece perceber isso com singular lucidez. O serviço de higiene mental criado no Rio de Janeiro, em virtude da reforma de Anísio Teixeira na rede municipal, tinha como objetivo servir como uma espécie de apoio das escolas primárias. Toda crian- 
ça identificada como criança problema deveria ser encaminhada para o respectivo órgão público. Nelas um estudo multidisciplinar procurava detectar as causas do comportamento tido como desajustado da criança no ambiente escolar.

Nestas clínicas de hábito são estudadas principalmente as bases fisiológicas da personalidade, as atividades instintivas primordiais, como fome, a sede, as funções de eliminação, o sono, o repouso, atividades de sexo, as primeiras manifestaçóes emocionais e afetivas, o desabrochar da inteligência. $O$ higienista mental orienta essas funçóes na formação de hábitos normais, corrigindo os precoces desajustamentos encontrados. (RAMOS, 1950, p. 23)

Ao que tudo indica, as chamadas clínicas de hábitos do Serviço de Higiene Mental objetivavam exercer um rigoroso controle sobre as crianças e jovens considerados como desajustados ou na eminência de alguns desvios devido à influência do meio. Nas clínicas havia uma preocupação constante em identificar, caracterizar e medir o grau de incidência dos comportamentos tidos como desajustados de crianças encaminhadas pelas escolas, pais e médicos:

Na clínica da Seção de Higiene Mental de São Paulo, tomada como paradigma nesta descrição, a ordem da incidência dos principais problemas é a seguinte, em escala decrescente: 1) conduta irregular na escola (abrangendo a desobediência, a rebeldia e a indisciplina em geral); 2) furto; 3) dificuldades de aprendizagem; 4) instabilidade psico-motora; 5) mentira; 6) enurese; 7) fugas (da escola e do lar, incluindo a gazeta); 8) problemas sexuais; 9) timidez; 10) tics; 11) sintomas histéricos: 12) fobias; 13) fantasia excessiva; 14) agressividade. (RAMOS, 1950, p. 45)

Para o pensador nordestino, uma das funçóes mais importantes da escola e da higiene mental era garantir a plena integração da criança à sociedade. Baseando-se nos estudos de Jean Piaget, ele identificou três estágios de desenvolvimento da linguagem infantil que compreendiam a repetição de palavras ou sílabas que criança ouve no seu ambiente de convívio, o monólogo em que o menor fala para si próprio e a monólogo a dois ou três. Nesta última fase as crianças falam mais de si e não estão preocupadas com as outras. Tratava-se da chamada linguagem egocêntrica que com a idade vai diminuindo, cedendo lugar à linguagem socializada. Contudo, mesmo o indivíduo na fase adulta pode manifestar traços de uma conversação egocêntrica, por isso a importância da psicanálise que se baseava na fala. Por meio da conversação era possível identificar os traços da personalidade.

Nas escolas os debates e diálogos eram incentivados como forma de estimular as crianças a se manifestarem e ao mesmo tempo ouvirem os colegas. Ramos cita o exemplo das comunidades de conversa desenvolvidas na escola experimental 
de Adler. Uma vez por semana as crianças eram estimuladas a conversarem entre si durante uma hora. No início tudo deveria ser controlado pelo professor, afim de que elas aprendessem a ouvir e a falar. A autonomia só seria concedida à medida que o grupo se mostrasse capaz de assim proceder sem recorrer à anarquia e indisciplina. Para o professor esta era uma excelente oportunidade de conhecer melhor seus alunos e, desta forma, encontrar meios mais eficientes de lidar com suas personalidades.

Mas não somente no sentido normativo ou prospectivo, à Adler, que a conversação tem tanta importância para o conhecimento da personalidade. Sabe-se que toda a psicanálise freudiana surgiu da "cura pela conversa" (talking cure), segundo a própria expressão de uma cliente do médico vienense. A palavra, como meio de comunicação intermental, transmite os desejos, as aspiraçôes, as tendências da pessoa que fala. E não só da sua personalidade consciente. Há também processos ocultos, inconscientes, reveláveis a quem conheça a significação esotérica ou oculta das palavras. Porque há palavras cifradas, recados do inconsciente. E essa técnica de decifração (chiffrier-methode) é também uma modalidade de conversa, um "diálogo com o inconsciente". (RAMOS, 1950, p. 174)

$\mathrm{Na}$ realidade o médico alagoano estava propondo que o professor das escolas públicas cariocas realizasse uma sessão de análise coletiva em sala de aula, identificando aí os possíveis problemas de seus alunos para, posteriormente, traçar uma estratégia de ação. Não era por acaso que ele insistia na ideia de que os cursos de formaçáo de professores tivessem uma disciplina dedicada à psicanálise. Havia a expectativa de que um mestre com formação adequada poderia identificar com mais rapidez os casos das crianças problema e, desta forma, prevenir possíveis casos de desajuste social dos menores.

Havia uma considerável preocupação com o grupo familiar, pois era nele que a criança estabelecia seus primeiros contatos e, assim, iniciava sua vida social. Embora não fosse direto em suas afirmativas, Arthur Ramos procurava demonstrar que a forma de organização familiar ideal para o pleno desenvolvimento infantil era a monogâmica. O médico Stekel, a quem o antropólogo brasileiro muitas vezes se referiu, compartilhava plenamente desta ideia.

Os pais servem de exemplos aos filhos; seu comportamento é, pois, decisivo para eles. Porém como educar geraçôes sadias quando o próprio educador não o é? Estigmatizar-me-ão talvez com a pecha de "moralista" porque sempre encarei a monogamia como única solução ética para o casamento. $\mathrm{O}$ autor que consagrou sua vida ao estudo das aberraçôes sexuais, e a quem 
nada do humano lhe é estranho, poderá aguentar esta crítica. (STEKEL, 1962, p. 6)

A monogamia era vista como a chave de uma vida familiar saudável, onde os filhos poderiam se desenvolver completamente. Ramos chamava a atenção para o fato de que as crianças não nascem seres sociáveis. Somente no contato com outras pessoas elas iam construindo novas relaçóes, aprendendo a conviver com as demais pessoas. A família, vista como um grupo social básico, nela um conjunto de "forças biológicas, psicológicas, sociológicas e culturais atua sobre o indivíduo, com uma intensidade extraordinária”. (RAMOS, 1950, p. 249) Por este motivo o grupo familiar chamava tanto a atenção do médico alagoano e de Durval Marcondes. Como unidade que possuía tanta influência sobre a formação do menor, era preciso que ela fosse acompanhada de perto, pois, como veremos, os pais eram os grandes responsáveis pelo comportamento dos filhos. Uma das funçóes do serviço chefiado por Ramos, no Departamento de Educação do Rio de Janeiro, era estudar a origem social das crianças e do lugar de onde vinham, pois tudo isso influía diretamente no desempenho escolar da criança.

É o que o Serviço de Higiene Mental do Departamento de Educação do Distrito Federal vem realizando nas suas indagaçóes sobre a vida extraclasse da criança, no sentido de estabelecer uma psicologia diferencial da criança da cidade e da criança das praias; da criança dos morros; dos níveis de vida e das condiçóes ambientais da criança que mora em casa individual e casa coletiva; em apartamentos ou casa de "cômodos" e "favelas". (RAMOS, 1952, pp. 250-251)

Os objetivos deste estudo apontado pelo autor não foram possíveis de identificar. Se haveria uma reorganização curricular, didática ou pedagógica das escolas públicas em função destas pesquisas realizadas pelo serviço de ortofrenia, também não foi possível precisar. Provavelmente o curto período de funcionamento do órgão não teria permitido que experiências do gênero fossem tentadas. O fato era que a atuação do referido serviço poderia fornecer subsídios para se repensar o trabalho pedagógico desenvolvido nas escolas e assim redirecionar a ação do Departamento de Educação, na época conduzido por Anísio Teixeira.

Em São Paulo a forma de atuação da clínica de higiene escolar não era muito diferente, embora não fosse tão contundente sobre o papel da família, Marcondes considerava que o estudo do local onde a criança vivia era fundamental para identificar a origem dos desajustamentos da criança na escola:

A pesquisa inicia-se ordinariamente pela investigação social. Compete à vistadora reconstruir, pelo interrogatório sistemático 
dos que têm contato com a criança, a evolução anterior do caso, pondo em relevo as diversas ocorrências prejudiciais que possam ter influído em seu desenvolvimento, assim como determinar as condiçôes do ambiente escolar que estejam contribuindo no mesmo sentido desfavorável. Essa indagação abrange o estudo individual das pessoas da família (pai, mãe, irmãos etc.), em tudo que diga respeito à sua atitude para com a criança e se relacione com a atmosfera psíquica do lar. (MARCONDES, 1946, pp. 45-46)

De qualquer forma, havia uma nítida preocupação em intervir no papel de instituição reguladora e normativa que era a família e a escola, que tinham uma grande responsabilidade na formação das crianças que seriam futuros adultos. $\mathrm{O}$ grau e intensidade desta intervenção dependiam de um estudo cientificamente embasado e preciso em suas conclusóes e que apontassem para os mecanismos mais eficientes de resolver os problemas identificados. No caso da clínica de São Paulo previa-se inclusive o afastamento da criança do convívio com os pais quando o trabalho dos técnicos junto à família do menor se mostrasse sem resultados.

Psicologicamente a escola continua o trabalho da família com que vem hoje intimamente unida. Ela é assim um processo socializante, visando integrar o indivíduo na comunidade, recapitulando os resultados da experiência social e transmitindo-lhe os padróes do grupo social e cultural a que pertence. Mas a escola de acordo com a concepçáo hodierna da educaçáo, náo é apenas uma guardiã da tradição ou uma perpetuadora dos padróes sociais presentes. Ela opera uma recapitulação da experiência para sua reconstruçáo (Dewey). Por isso ela é um instrumento consciente de aperfeiçoamento social; a sua tarefa é orgânica, vital, por excelência. A sua transformação técnica é reclamada pelas exigências desta fase histórica de profunda transição. Daí os debates encarniçados sobre a finalidade da escola e o problema agudo da pedagogia dirigida. É o trágico conflito da hora presente entre a educação para os quadros democráticos, e a educação "dirigida", para Deus, para a Máquina ou para o Estado Totalitário. (RAMOS, 1952, p. 252)

Neste fragmento o médico-antropólogo sintetiza os principais objetivos da escola na opinião dos pioneiros da Escola Nova e seus embates com os católicos e o próprio governo de Vargas, tido por ele como "totalitário". Tratava-se de um momento único na história brasileira em que as possibilidades de avançar e adentrar na modernidade industrial e urbana era possível, como também era inadmissível a manutenção de um modelo tradicional de educação conduzido pela mão forte da ditadura e apoiada pela Igreja Católica. A tão sonhada sociedade industrializada também se implantou, porém timidamente democrática, extrema- 
mente desigual e com uma educação repleta de rupturas, de reformas infrutíferas e de precários resultados.

\section{Considerações finais}

A obra de Arthur Ramos tem méritos importantes, como de romper com conceito tido como inquestionável de anormalidade e questionar a aplicação dos testes de Q.I., além de apresentar e utilizar a psicanálise na educação. Em uma época ainda muito conservadora, falava com naturalidade de termos como libido, recalques, desejos sexuais, e divulgar estas ideias de uma forma mais didática possível não parece ser pouco. Intelectual engajado nas causas sociais e políticas de seu tempo, ele não considerava o que fazia a última palavra naquele assunto. Reconhecia o caráter provisório do conhecimento científico. Não deixou discípulos e não fez questão de cultivá-los, morreu muito cedo e tudo isso contribuiu para o ostracismo a que suas obras foram condenadas até os dias atuais.

Percorrendo os rastros da relação entre educação e saber médico no país vamos encontrando os indícios de um longo e intenso diálogo que não se resumia apenas na produção de um discurso crítico sobre a qualidade das escolas públicas. Imbuídos de uma formação essencialmente cientificista e empolgados com as possibilidades do emprego das ciências do comportamento, os médicos vislumbravam uma nova realidade social para a nação que pudesse retirá-la da condição de "atraso" em que se encontrava. Entre as várias possibilidades de alavancar essas propostas a educação parecia ser a forma mais eficiente de promover as transformaçóes que se faziam necessárias, e o trabalho com as crianças indicava ser o mais promissor. Os indivíduos pequenos ainda em formação deveriam ser a prioridade de toda e qualquer ação governamental com o objetivo não só de indicar qual a melhor educação, mas também intervir sempre que necessário para corrigir possíveis erros e indicar os procedimentos a serem efetivados.

Os adultos, em especial os pais, eram peças importantes desses projetos. Em muitos casos era melhor cuidar dos genitores do que das crianças, pois elas eram por eles formadas. No caso dos médicos-psicanalistas, como Marcondes e Ramos, leitores de Freud e seus discípulos como Anna Freud e Melaine Klein, a terapia das crianças era feita com os adultos, pois essa era a forma mais eficiente de tratar menores com problemas comportamentais e de desajuste. Havia uma clara noção de que os indivíduos mais jovens poderiam ser plenamente moldáveis. Tudo iria depender do ambiente em que viviam, da instituição onde estudavam e das pessoas que os cercavam. Embora houvesse um exagero nessa concepção de um ser totalmente adaptável às condiçôes do meio, essa visão da criança, como um ser em formação, que tem de ser protegida e que tem prioridade nas políticas públicas, é um dos princípios que estão embutidos hoje na legislação para esse segmento da 
população. Aqui fica claro o caráter essencialmente humanista desses intelectuais que nem sempre é levado em consideração em estudos recentes sobre os referidos autores.

Provavelmente tais clínicas não mais seriam possíveis dada a expansão dos serviços de saúde e da proliferação dos profissionais da psicologia. Além do que é preciso considerar o gigantismo de muitas redes escolares que chegam a atender milhóes de alunos, como é o caso de São Paulo. No entanto, algumas das características das clínicas de Durval Marcondes e Arthur Ramos poderiam ser retomadas em novos moldes, como era o caso das equipes multidisciplinares. Constituídas por médicos, psicólogos, pedagogos, assistentes sociais e outros profissionais que seriam importantes na solução de graves problemas por que passam hoje as escolas públicas com o aumento assustador da violência em seu interior. Equipes assim poderiam agir nos casos mais críticos, estudando as condiçóes do local e propondo açóes possíveis de serem ali executadas com o envolvimento de toda comunidade escolar. A carência desse tipo de profissional é notória nas escolas públicas e poderia trazer novas possibilidades de fazer avançar a qualidade da educação tão necessária ao crescimento do país.

\section{Referências}

BOURDIEU, P. A economia das trocas simbólicas. 2 ed. São Paulo: Perspectiva, 1987.

BOURDIEU, P. Coisas ditas. São Paulo: Brasiliense, 2004.

DÁVILA, J. Diploma de brancura. São Paulo: Unesp, 2006.

MARCONDES, D. Noçôes gerais de higiene mental da criança. São Paulo: Martins, 1946.

MICELI, S. A força do sentido. In: BOURDIEU, P. A economia das trocas simbólicas. 2 ed. São Paulo: Perspectiva, 1987.

MOKREJS, E. A Divulgação das primeiras idéias psicanalíticas no Brasil. 1986. 398f. Tese (Doutorado em Educação) - Faculdade de Educação, Universidade de São Paulo. São Paulo. 1986.

RAMOS, A. Introdução à psicologia social. Rio de Janeiro: Casa do Estudante do Brasil, 1952.

SAGAWA, R. Y. Durval Marcondes. Rio de Janeiro: Imago, 2002.

STEKEL, W. A educação dos pais. São Paulo: Mestre Jou, 1962.

Recebido em 31 de julho de 2013.

Aprovado em 24 de outubro de 2014. 